\title{
Avaliação da qualidade do carvão vegetal de Qualea parviflora
}

\author{
Thiago de Paula Protásio, João de Deus Pereira de Santana², Rosalvo Maciel Guimarães Neto², \\ José Benedito Guimarães Júnior², Paulo Fernando Trugilho', loleide Bispo Ribeiro² \\ ${ }^{1}$ Universidade Federal de Lavras (UFLA), Departamento de Ciências Florestais, CP 3037, CEP 37200-000, Lavras, MG, Brasil \\ ${ }^{2}$ Universidade Federal do Piauí (UFPI), Câmpus Professora Cinobelina Elvas, CEP 64900-000, Bom Jesus, PI, Brasil
}

"Autor correspondente:
depaulaprotasio@gmail.con

Termos para indexação:

Pirólise

Correlações

Amostragem

Modelos

\section{Index terms:}

Pyrolysis

Correlations

Sampling

Models

Histórico do artigo:

Recebido em 12 mai 2011

Aprovado em 14 set 2011

Publicado em 28 dez 2011

doi: 10.4336/2011.pfb.31.68.295
Resumo - Os objetivos desse trabalho foram verificar a influência da posição longitudinal de amostragem em Qualea parviflora Mart. na qualidade do carvão vegetal e as relações estatísticas entre as variáveis mensuradas nesse biocombustível. Foram avaliadas cinco árvores das quais foram retirados discos de $5 \mathrm{~cm}$ de espessura na base, DAP $(1,30 \mathrm{~m})$, meio e topo. A madeira foi carbonizada em uma mufla, considerando a taxa de aquecimento de $1,67^{\circ} \mathrm{C} \mathrm{min}^{-1}$. Foram contabilizados os rendimentos em carvão, em líquido pirolenhoso, em gases não condensáveis e em carbono fixo e os teores de materiais voláteis, carbono fixo e cinza, além da densidade relativa aparente do carvão. $\mathrm{Na}$ avaliação do experimento utilizou-se um delineamento inteiramente casualizado com cinco repetições, tendo como fator de variação as posições de amostragem. Foram avaliadas as correlações lineares simples entre as características mensuradas e propostos modelos estatísticos. O carvão de Qualea parviflora apresentou grande potencial energético. Não foi constatada influência significativa da posição longitudinal de amostragem na qualidade do carvão. Deve-se considerar o teor de carbono fixo, o rendimento gravimétrico e o teor de materiais voláteis como as principais características relacionadas ao poder calorífico superior do carvão vegetal avaliado.

\section{Evaluation of the quality of Qualea parviflora charcoal}

\begin{abstract}
This work aimed to verify the influence of the sampling longitudinal position in Qualea parviflora Mart. in the quality of charcoal and the statistical relation among the variables measured in this biofuel. Five trees were evaluated. In each one, $5 \mathrm{~cm}-$ thickness discs were obtained in the base, DBH $(1.30 \mathrm{~m})$, middle and top. The wood was carbonized in a muffle furnace, considering a heating rate of $1.67{ }^{\circ} \mathrm{C} \mathrm{min}{ }^{-1}$. The yields in charcoal pyroligneous extract, in non-condensable gases and in fixed carbon and volatile matters, fixed carbon and ash contents, besides relative apparent density of the charcoal were determined. In the evaluation of the experiment, an entirely randomized design was used with five repetitions, being different sampling position considered a variation factor. Simple linear correlations between characteristics measured in the charcoal were evaluated and statistical models were proposed. Charcoal from Qualea parviflora Mart. wood presented great energetic potential. A significant influence of the sampling longitudinal position Qualea parviflora Mart. in the quality of the charcoal was not found. Fixed carbon content, gravimetric yield and volatile matter contents must be considered main characteristics related to higher heating value of the charcoal evaluated.
\end{abstract}




\section{Introdução}

A madeira participa de forma importante na matriz energética mundial, com maior ou menor intensidade, dependendo da região considerada. Seu uso é afetado por variáveis como: nível de desenvolvimento do país, disponibilidade de florestas, questões ambientais e competição econômica com outras fontes energéticas, como petróleo, gás natural, hidroeletricidade e energia nuclear (Brito, 2007).

O carvão vegetal é uma fonte energética de grande importância no Brasil, por ser renovável e também devido a sua importância histórica e econômica no país. Aproximadamente $90 \%$ do carvão vegetal produzido no Brasil é utilizado no setor siderúrgico, uma vez que ele é o agente de dupla finalidade para a produção de ferro gusa e aço, fornecendo calor para o sistema, além de reduzir o minério de ferro (Pinheiro et al., 2006).

No entanto, as plantações florestais homogêneas não são capazes de suprir toda a demanda das empresas, havendo um déficit anual médio de quase 50\% (cerca de 19 milhões de metro estéreo de carvão) que é suprido com resíduos e manejo de florestas naturais (Calais, 2009). Além disso, com o aumento de produtividade, os setores como o de ferro gusa e aço consomem grandes quantidades de carvão vegetal e estão cada vez mais exigentes quanto à qualidade do carvão vegetal produzido, pois este influencia diretamente no produto final e nos custos do processo produtivo.

Dessa maneira, torna-se extremamente importante a obtenção de um carvão vegetal que atenda as exigências do mercado consumidor, e a sua produção deve ter um padrão de qualidade desde a matéria-prima (madeira) utilizada até o controle total do processo.

A escolha de espécies arbóreas que forneçam madeira para produção de carvão de boa qualidade é cada vez mais estudada. Qualea parviflora apresenta alta densidade básica $\left(690 \mathrm{~kg} \mathrm{~m}^{-3}\right)$ e significativa produção de massa seca por hectare (Vale et al., 2000; Vale et al., 2002), sendo que quanto maior a densidade básica da madeira, maior será a densidade aparente do carvão (Brito \& Barrichelo, 1980; Vale et al., 2001; Vale et al., 2010). A produção de massa seca também é fundamental para a escolha e classificação de espécies para a produção de carvão vegetal, pois apresenta altas correlações com a massa de lignina na madeira e com a massa de carvão vegetal por árvore ou hectare (Trugilho et al., 2001). O teor de lignina, por sua vez, influencia diretamente no rendimento gravimétrico em carvão vegetal (Brito \& Barrichelo, 1977; Oliveira et al., 1989).

Qualea parviflora é uma espécie de grande ocorrência na zona de transição entre os biomas Cerrado e Caatinga. Segundo Lorenzi (2002), é conhecida popularmente como pau-terra-de-folha-miúda ou pau-terra. É uma espécie pertencente à família Vochysiaceae e ocorre naturalmente na Bahia, Minas Gerais, Mato Grosso do Sul, Piauí e São Paulo, nos cerrados e campos cerrados.

Há uma ausência na literatura de trabalhos relacionados à produção e avaliação do carvão de Qualea parviflora. Além disso, a madeira de muitas espécies apresenta grande variabilidade tanto no sentido medula-casca quanto base-topo, podendo influenciar na qualidade do carvão.

Portanto, os objetivos desse trabalho foram verificar a influência da posição longitudinal de amostragem em Qualea parviflora na qualidade do carvão vegetal e as relações estatísticas entre as variáveis mensuradas nesse biocombustível como subsídio para predições e interpretações de interesse científico.

\section{Material e métodos}

\section{Carbonizações e avaliação do carvão vegetal produzido}

Foi utilizada madeira de árvores provenientes de um remanescente de cerrado localizado entre os municípios de Bom Jesus e Currais, no Estado do Piauí. Foram avaliadas cinco árvores-amostra coletadas ao acaso, das quais foram retirados discos de $5 \mathrm{~cm}$ de espessura nas posições de amostragem relativas à base, diâmetro a 1,30 $\mathrm{m}$ de altura (DAP), meio e topo, considerando-se a altura total das árvores (em média 5,38 m), totalizando cinco repetições por posição de amostragem longitudinal. $\mathrm{O}$ DAP médio com casca foi de $51,0 \mathrm{~cm}$ e sem casca de $40,4 \mathrm{~cm}$. A altura considerada para a amostragem inclui apenas o tronco das árvores.

A madeira foi carbonizada em um forno elétrico tipo mufla, considerando a taxa de aquecimento de $1,67^{\circ} \mathrm{C} \mathrm{min}{ }^{-1}$. A temperatura inicial foi $100{ }^{\circ} \mathrm{C}$ e a final de $450{ }^{\circ} \mathrm{C}$, permanecendo estabilizada por 30 minutos (Trugilho et al., 2001; Trugilho et al., 2005; Botrel et al., 2007). O tempo total de carbonização foi de 4 horas. Foi utilizado em cada ensaio aproximadamente $800 \mathrm{~g}$ de madeira, previamente seca em estufa a 103 $\pm 2{ }^{\circ} \mathrm{C}$. Após cada carbonização foi contabilizado o rendimento gravimétrico em carvão vegetal $(\mathrm{RG})$, em 
líquido pirolenhoso (RLP) e, por diferença, o rendimento em gases não condensáveis (RGNC), todos em relação à massa de madeira seca. Também foi determinado o rendimento em carbono fixo (RCF).

A densidade relativa aparente (DRA) do carvão vegetal foi determinada pelo método hidrostático, considerando a água como meio, conforme descrito por Vital (1984).

Procedeu-se a análise imediata do carvão vegetal para a quantificação dos teores de carbono fixo (TCF), materiais voláteis (TMV) e cinza (TCZ), segundo as diretrizes da norma NBR 8112 (Associação Brasileira de Normas Técnicas, 1983).

Para a quantificação do poder calorífico superior (PCS), foi utilizado um calorímetro digital da marca IKA C-200 sendo o ensaio padronizado com a norma NBR 8633 (Associação Brasileira de Normas Técnicas, 1984).

$\mathrm{Na}$ avaliação do experimento, utilizou-se o delineamento inteiramente casualizado com cinco repetições e considerando como fator de variação as diferentes posições longitudinais de amostragem. Para a comparação múltipla das médias, foi utilizado o teste de Tukey em nível de 5\% de significância.

\section{Análises de correlação e regressão linear simples e múltipla}

Foram avaliados os coeficientes de correlação linear simples de Pearson entre as características mensuradas. Com base nos coeficientes de correlação linear, foram propostos modelos estatísticos lineares simples e múltiplos para a predição e interpretação das variáveis de interesse (Tabela 1).

Os modelos foram avaliados com base na significância de todos os seus coeficientes, no coeficiente de determinação ajustado ( $\mathrm{R}^{2}$ ajust), no erro padrão da estimativa (Sxy), no coeficiente de variação, na normalidade (Teste Shapiro Wilk), presença de variâncias desiguais, ou seja, heterocedasticidade (Teste
Goldfeld-Quandt) e ausência de autocorrelação (Teste Durbin-Watson) dos resíduos dos modelos ajustados. Também foram avaliados os sinais algébricos de todos os coeficientes angulares dos modelos como forma de entender o relacionamento entre as variáveis.

Tabela 1. Modelos estatísticos lineares propostos.

\begin{tabular}{cc}
\hline $\begin{array}{c}\mathbf{N}^{\mathbf{0}} \text { do } \\
\text { modelo }\end{array}$ & Modelos estatísticos propostos \\
\hline 1 & $\mathrm{PCS}=\beta_{0}+\beta_{1} \mathrm{TCF}+\varepsilon$ \\
2 & $\mathrm{PCS}=\beta_{0}+\beta_{1} \mathrm{TMV}+\varepsilon$ \\
3 & $\mathrm{PCS}=\beta_{0}+\beta_{1} \mathrm{RG}+\varepsilon$ \\
4 & $\mathrm{TCF}=\beta_{0}+\beta_{1} \mathrm{RG}+\varepsilon$ \\
5 & $\mathrm{TMV}=\beta_{0}+\beta_{1} \mathrm{RG}+\varepsilon$ \\
6 & $\mathrm{PCS}=\beta_{0}+\beta_{1} \mathrm{TCF}+\beta_{2} \mathrm{RG}+\varepsilon$ \\
7 & $\mathrm{PCS}=\beta_{0}+\beta_{1} \mathrm{TMV}+\beta_{2} \mathrm{RG}+\varepsilon$ \\
\hline
\end{tabular}

PCS: poder calorífico superior $\left(\mathrm{kcal} \mathrm{kg}^{-1}\right)$; TCF: teor de carbono fixo (\%); TMV: teor de materiais voláteis (\%); RG: rendimento gravimétrico em carvão $\operatorname{vegetal}(\%) ; \beta_{0}, \beta_{1,} \beta_{2}$ : coeficientes dos modelos; $\varepsilon$ : erro do modelo.

Todas as análises estatísticas foram efetuadas utilizando o software estatístico $\mathrm{R}$ versão 2.11.0 (R Development Core Team, 2008) e na avaliação dos pressupostos da análise de regressão utilizou-se o pacote lmtest (Hothorn et al., 2010). Os modelos lineares propostos foram ajustados com base no método dos mínimos quadrados ordinários (MQO) que visa à minimização do erro.

\section{Resultados e discussão}

\section{Carbonizações e avaliação do carvão vegetal produzido}

Os rendimentos e características gerais encontradas para o carvão de Qualea parviflora estão apresentados na Tabela 2. Observam-se, de maneira geral, baixos coeficientes de variação para as características e rendimentos.

Tabela 2. Rendimentos e características gerais encontradas para o carvão de Qualea parviflora.

\begin{tabular}{cccccccccc}
\hline Estatísticas & RG & RLP & RGNC & RCF & DRA & TCF & TMV & TCZ & PCS \\
\hline Média Geral & 34,60 & 40,97 & 24,43 & 26,23 & 410,70 & 75,89 & 21,18 & 2,93 & 7259,10 \\
CV(\%) & 3,74 & 6,33 & 11,67 & 3,04 & 9,77 & 3,68 & 13,22 & 13,42 & 2,92 \\
Erro Padrão & 0,30 & 1,30 & 1,43 & 0,18 & 9,20 & 0,64 & 0,64 & 0,09 & 48,59 \\
\hline
\end{tabular}

RG, RLP, RGNC, RCF: rendimento gravimétrico em carvão vegetal (\%), em líquido pirolenhoso (\%), em gases não condensáveis e em carbono fixo (\%), respectivamente; DRA: densidade relativa aparente $\left(\mathrm{kg} \mathrm{m}^{-3}\right)$; TCF, TMV, TCZ: teor de carbono fixo (\%), de materiais voláteis (\%) e de cinza $(\%)$, respectivamente; PCS: poder calorífico superior $\left(\mathrm{kcal} \mathrm{kg}^{-1}\right)$. 
Para a produção, geralmente, é desejável obter elevado rendimento gravimétrico em carvão vegetal, devido ao maior aproveitamento da madeira nos fornos de carbonização e, consequentemente, maior produção de energia e menores rendimentos em líquido e em gases não condensáveis, pois esses são subprodutos do processo de pirólise. Contudo, o rendimento gravimétrico sofre influência da temperatura e do tempo de carbonização (Oliveira et al., 2010), sendo que maiores temperaturas implicam em menores rendimentos e maior teor de carbono fixo e, consequentemente, maior poder calorífico. Os valores médios do rendimento gravimétrico em carvão vegetal, em líquido pirolenhoso e em gases não condensáveis estão próximos ao encontrado para clones de Eucalyptus (Trugilho et al., 2001; Botrel et al., 2007). Essa espécie também apresenta a grande vantagem de ser nativa do cerrado brasileiro e, consequentemente, adaptada as características edafoclimáticas desse bioma.

Combustíveis com altos teores de carbono fixo e baixos teores de materiais voláteis tendem a se queimar mais lentamente, ou seja, eles poderão requerer longo tempo de residência na fornalha para a queima total, quando comparados com combustíveis que possuam baixo índice de carbono fixo (Nogueira \& Lora, 2003; Brand, 2010). O conhecimento da composição química imediata é importante para o cálculo do projeto da fornalha e das quantidades de ar primário e secundário, necessários em função da percentagem de voláteis, caso o carvão vegetal seja utilizado, por exemplo, na geração de calor ou eletricidade em termelétricas ou sistemas de geração de energia (Brand, 2010). Portanto, o rendimento em carbono fixo e o teor de materiais voláteis são características indispensáveis na avaliação energética do carvão vegetal. Para vários clones de Eucalyptus, o rendimento médio em carbono fixo mencionado na literatura é de aproximadamente $26 \%$ (Trugilho et al., 2005; Botrel et al., 2007), corroborando o encontrado no presente trabalho.

Botrel et al. (2007), utilizando a mesma taxa de aquecimento do forno mufla e o mesmo tempo total de carbonização, encontraram teor médio de carbono fixo para clones de Eucalyptus de 74,25\%, semelhante ao encontrado neste trabalho. Contudo, Trugilho et al. (2005) e Brito et al. (1983) relataram valores inferiores em clones e espécies de Eucalyptus. Já Trugilho et al. (2001), utilizando a mesma taxa e tempo total de carbonização, encontraram teor médio de carbono fixo superior para o carvão vegetal de clones de Eucalyptus. Isso ocorreu provavelmente devido à composição química e física da madeira utilizada.

A análise do teor de cinza é imprescindível na avaliação energética do carvão, uma vez que altos teores contribuem para a redução do poder calorífico, visto que os materiais minerais não participam da combustão, mas são contabilizados na massa do combustível (Protásio et al., 2011; Brand, 2010). São comumente encontrados na literatura baixos teores de cinzas $(0,16 \%$ a $1 \%)$ para o carvão de vários clones e espécies de Eucalyptus (Brito \& Barrichelo, 1977; Vale et al., 1996; Trugilho et al., 2001; Trugilho et al., 2005; Botrel et al., 2007), muito inferiores ao valor médio para o carvão vegetal de Qualea parviflora. O teor de cinza para o carvão vegetal de Qualea grandiflora, encontrada por Vale et al. (2001) é de $0,7 \%$, inferior em aproximadamente $319 \%$ ao obtido nesse trabalho. Já o poder calorífico superior para o carvão vegetal de Qualea parviflora assemelhase ao encontrado para o carvão de Qualea grandiflora (7387 kcal kg-1) (Vale et al., 2001)

Elevado valor de densidade relativa aparente do carvão vegetal é desejável devido à quantidade de energia disponível por volume (densidade energética) e maior resistência do carvão à abrasão nos fornos siderúrgicos. O carvão de Qualea parviflora apresentou elevada densidade relativa aparente. Os valores médios inferiores do carvão de Eucalyptus (Brito et al., 1983; Trugilho et al., 2005; Botrel et al., 2007) demonstram a potencialidade da espécie estudada. No entanto, Trugilho et al. (2001) observaram densidade relativa aparente média de $448 \mathrm{~kg} \mathrm{~m}^{-3}$ para dez clones de Eucalyptus, superior ao do carvão de Qualea parviflora.

$O$ rendimento gravimétrico em carvão vegetal obtido para as diferentes posições longitudinais está apresentado na Figura 1. 


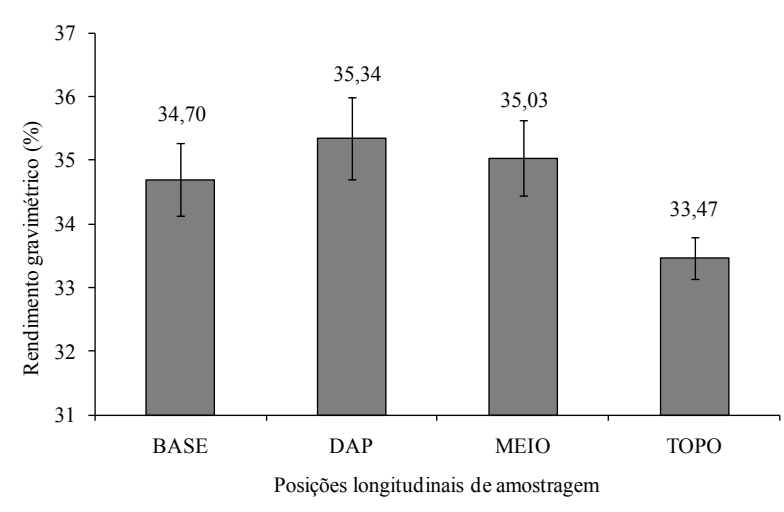

Figura 1. Médias dos rendimentos gravimétricos em carvão vegetal observadas nas quatro diferentes posições de amostragem.

O efeito da posição longitudinal de amostragem no rendimento gravimétrico em carvão vegetal não foi significativo. Esse resultado indica que para produção de carvão vegetal pode-se utilizar a madeira advinda das diferentes posições longitudinais de amostragem. Contudo, observou-se que o rendimento gravimétrico encontrado para a madeira retirada do topo da árvore foi inferior ao encontrado para as demais posições. Isso ocorreu, possivelmente, devido à variação na composição química da madeira no sentido longitudinal, principalmente o teor de lignina que exerce influência direta no rendimento gravimétrico em carvão vegetal (Brito \& Barrichelo, 1977; Oliveira et al., 1989). Além disso, há uma tendência de maior proporção de madeira juvenil no topo das árvores que, geralmente, apresenta menor densidade, sendo que quanto menor a densidade básica, menor o rendimento gravimétrico e o teor de lignina (Oliveira et al., 1989).

O rendimento em carvão vegetal no Brasil é em média 35\% (Rosillo-Calle \& Bezzon, 2005), sendo próximo ao encontrado no presente trabalho para o carvão das diferentes posições longitudinais de amostragem.

As médias dos rendimentos em carbono fixo do carvão vegetal nas diferentes posições longitudinais de amostragem em Qualea parviflora encontram-se na Figura 2.

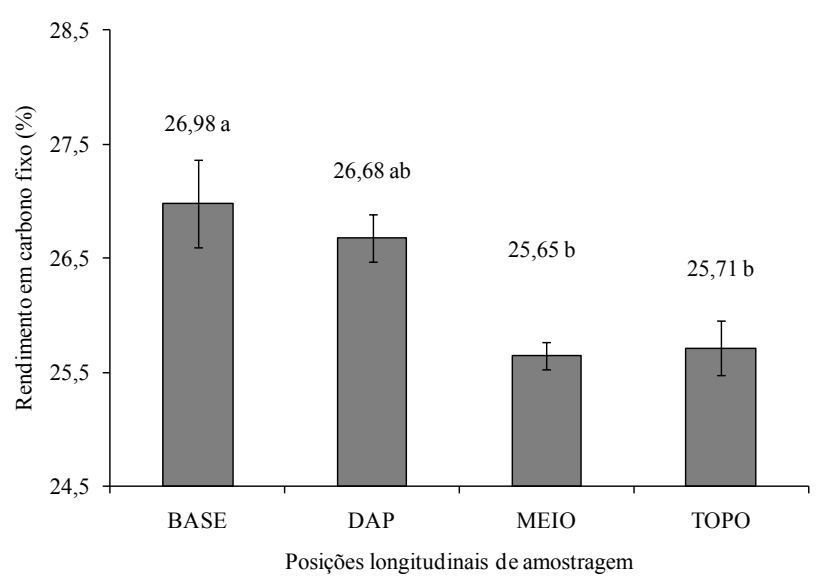

Figura 2. Médias dos rendimentos em carbono fixo do carvão vegetal observadas nas quatro diferentes posições longitudinais de amostragem. Médias seguidas pela mesma letra não diferem entre si a 5\% de significância pelo Teste de Tukey.

Verificou-se que existe diferença significativa (a 95\% de confiança) para o efeito da posição longitudinal de amostragem no rendimento em carbono fixo. Observase que o maior rendimento em carbono fixo foi encontrado na base da árvore, enquanto que os menores rendimentos foram determinados para o carvão vegetal oriundo do meio e topo das árvores, correspondendo a uma diferença média de 5,06\%. Vale et al. (2001) encontraram rendimento em carbono fixo médio para Qualea grandiflora de 28,63\%, sendo superior em aproximadamente $6 \%$ ao encontrado nesse trabalho para o carvão vegetal obtido pela carbonização da madeira advinda da base das árvores. A avaliação dessa característica é essencial para a viabilidade energética do carvão vegetal, pois quanto maior for o rendimento em carbono fixo, maior será a quantidade de energia produzida.

As médias das densidades relativas aparentes do carvão vegetal nas diferentes posições longitudinais de amostragem encontram-se na Figura 3. 


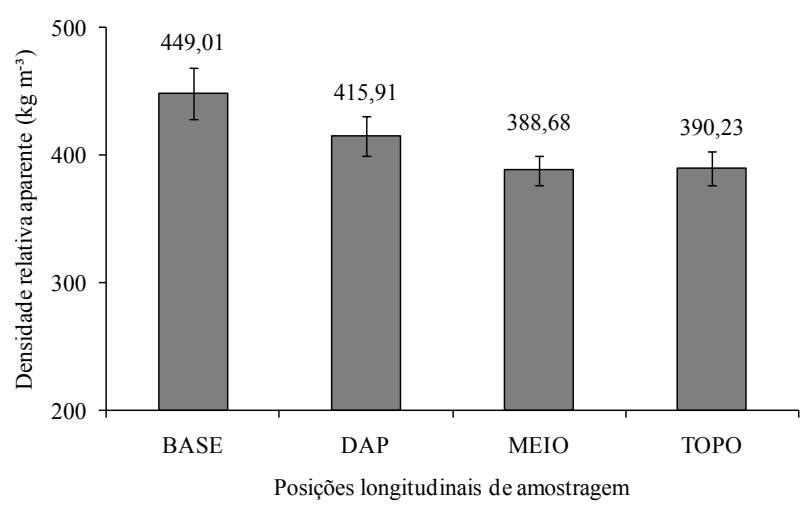

Figura 3. Médias das densidades relativas aparentes do carvão vegetal observadas nas quatro diferentes posições longitudinais de amostragem.

O efeito da posição longitudinal de amostragem foi significativo para a densidade relativa aparente a $5 \%$ de significância ( $\mathrm{p}$-valor $=0,0413$ ). No entanto, as médias apresentaram-se iguais a 5\% de significância pelo Teste de Tukey (diferença mínima significativa igual a 68,29), mas é possível perceber que a densidade relativa do carvão tende a decrescer da base para o topo da árvore em aproximadamente $15 \%$. Isso ocorreu, provavelmente, devido à variação longitudinal da densidade da madeira utilizada que resultou na variação da densidade relativa aparente do carvão (Brito \& Barrichelo, 1980; Vale et al., 2001; Vale et al., 2010).

A densidade relativa aparente do carvão vegetal obtida na base das árvores de Qualea parviflora assemelha-se ao valor encontrado para Dalbergia miscolobium de 440 $\mathrm{kg} \mathrm{m}^{-3}$ (Vale et al., 2001). Contudo, a densidade aparente do carvão vegetal obtido da posição central das árvores de Qualea parviflora foi superior em 15\% ao encontrado para Blepharocalix salicifolia (Vale et al., 2001).

As médias dos teores de carbono fixo do carvão vegetal observadas nas diferentes posições de amostragem encontram-se na Figura 4.

O efeito da posição longitudinal de amostragem não foi significativo a $5 \%$ pelo Teste $\mathrm{F}$ para o teor de carbono fixo. Contudo, observa-se tendência de decréscimo até o meio da árvore, seguido de acréscimo até o topo. O coeficiente de variação experimental encontrado $(3,13 \%)$ foi baixo. Isso é um indício da alta precisão do experimento (Pimentel-Gomes, 2009). Para espécies arbóreas do bioma cerrado, o teor médio de carbono fixo encontrado na literatura é de $74,72 \%$ (Vale et al., 2001) e assemelha-se ao encontrado neste trabalho. O teor de carbono fixo de $77,77 \%$ obtido por Vale et al. (1996) para o carvão vegetal de Eucalyptus grandis é semelhante ao da base das árvores de Qualea parviflora.

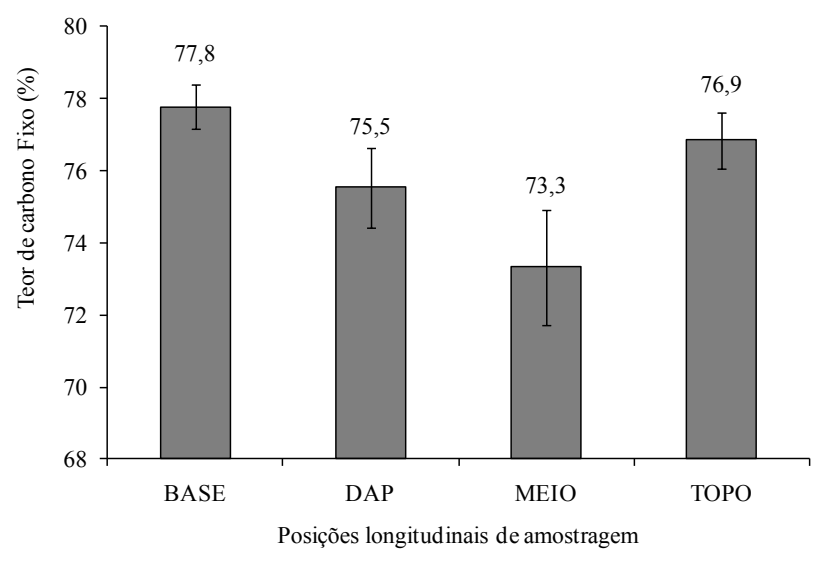

Figura 4. Médias dos teores de carbono fixo do carvão vegetal observadas nas quatro diferentes posições longitudinais de amostragem.

O carvão vegetal usado na fabricação de aço e ferrogusa deve ter um teor de carbono fixo superior a $75 \%$ (Rosillo-Calle \& Bezzon, 2005). Diante disso, o carvão vegetal de Qualea parviflora das partes mais basais é mais indicado para essa finalidade.

Os valores médios dos teores de materiais voláteis do carvão vegetal nas quatro posições longitudinais de amostragem estão apresentados na Figura 5.

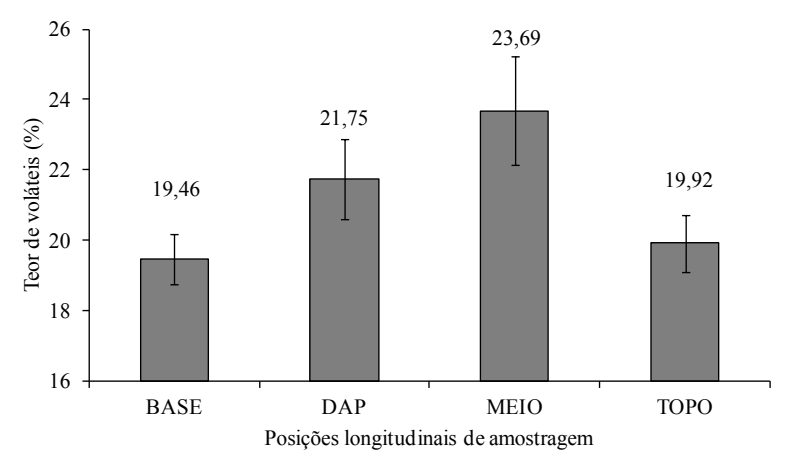

Figura 5. Médias dos teores de materiais voláteis do carvão vegetal observadas nas quatro diferentes posições longitudinais de amostragem.

O efeito da posição longitudinal de amostragem não foi significativo a $5 \%$ pelo Teste $\mathrm{F}$ para o teor de materiais voláteis. O coeficiente de variação experimental encontrado foi de $11,28 \%$ e sugere a precisão do experimento, podendo ser considerado como 
médio (Pimentel-Gomes, 2009). A tendência encontrada para o teor de materiais voláteis é contrária à encontrada para o teor de carbono fixo, pois essas variáveis são inversamente proporcionais (Trugilho \& Silva, 2001; Vale et al., 2001; Brand, 2010). O teor médio de materiais voláteis para o carvão de Dalbergia miscolobium e Sclerolobium paniculatum $(24,26 \%)$ foi superior ao encontrado neste trabalho (Vale et al., 1996). Já o valor médio de materiais voláteis para o carvão de Schefflera macrocarpa $(21,5 \%)$ é semelhante ao obtido para a média das posições deste trabalho (Vale et al., 2001).

Os valores médios dos teores de cinzas do carvão vegetal observados nas diferentes posições longitudinais de amostragem estão apresentados na Figura 6.

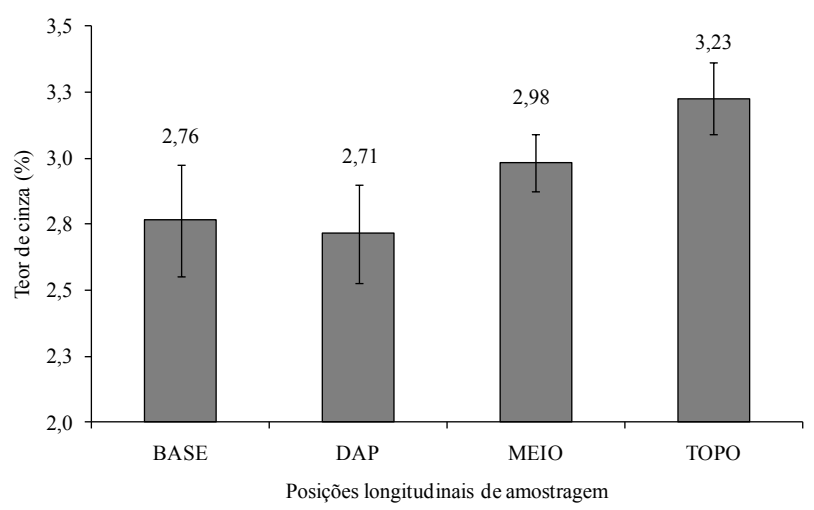

Figura 6. Médias dos teores de cinza do carvão vegetal observadas nas quatro diferentes posições longitudinais de amostragem.

Pela análise de variância, verificou-se que não existe diferença significativa (a 95\% de confiança) para o efeito da posição longitudinal de amostragem no teor de cinza do carvão vegetal. Entretanto, observa-se uma tendência de aumento no sentido da base-topo. Isso pode ter ocorrido, possivelmente, devido à maior porcentagem de madeira juvenil em relação à madeira adulta no topo das árvores. O teor médio de cinza para o carvão vegetal da espécie Blepharocalix salicifolia (2,93\%) é semelhante ao encontrado no carvão vegetal proveniente da base, DAP e meio das árvores de Qualea parviflora (Vale et al., 2001). Já para o carvão vegetal das espécies Dalbergia miscolobium e Sclerolobium paniculatum, ambas de ocorrência no bioma cerrado, o teor de cinza, obtido na literatura, de $0,33 \%$ e $1,16 \%$, respectivamente, é inferior ao encontrado neste trabalho (Vale et al., 1996).
Os valores médios do poder calorífico superior do carvão vegetal nas diferentes posições longitudinais de amostragem nas árvores de Qualea parviflora estão apresentados na Figura 7.

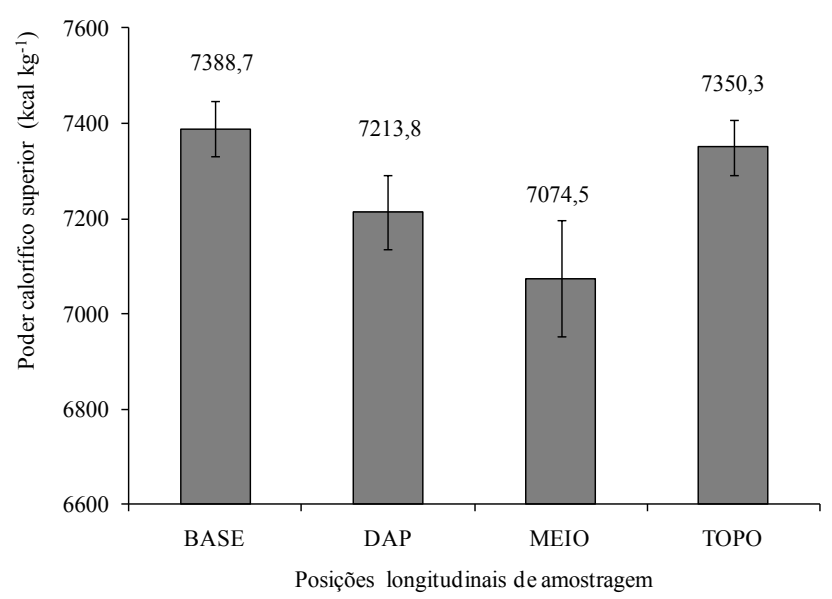

Figura 7. Médias do poder calorífico superior do carvão vegetal observadas nas quatro diferentes posições longitudinais de amostragem.

Verificou-se que não existe diferença significativa (a 95\% de confiança), pela análise de variância, para o efeito da posição longitudinal de amostragem no poder calorífico superior. No entanto, observa-se decréscimo da base até o meio da árvore (Figura 7), correspondendo a uma diferença de $314,20 \mathrm{kcal} \mathrm{kg}^{-1}$. Para efeito prático de uso da biomassa em sistemas de geração de energia como termelétricas ou gaseificadores, são consideradas diferenças significativas no poder calorífico os valores superiores a $300 \mathrm{kcal} \mathrm{kg}^{-1}$ (Brand, 2010), sendo que esse entendimento pode ser utilizado de forma análoga ao carvão vegetal. Observa-se ainda que o comportamento do poder calorífico no sentido base-topo foi similar ao encontrado para o teor de carbono fixo, uma vez que essas variáveis são altamente correlacionadas (Trugilho \& Silva, 2001; Vale et al., 2001).

O poder calorífico superior médio do carvão vegetal proveniente do meio das árvores de Qualea parviflora é semelhante ao de Blepharocalix salicifolia $(7047 \mathrm{kcal}$ $\mathrm{kg}^{-1}$ ) (Vale et al., 2001). Já o poder calorífico superior do carvão vegetal de Hymenaea stigonocarpa $(7445 \mathrm{kcal}$ $\mathrm{kg}^{-1}$ ) (Vale et al., 2001) assemelha-se ao da base e topo das árvores de Qualea parviflora. 


\section{Análises de correlação e regressão linear simples e múltipla}

$\mathrm{Na}$ Tabela 3 encontram-se os coeficientes de correlação linear simples de Pearson entre as variáveis avaliadas no carvão vegetal proveniente das diferentes posições longitudinais de amostragem.

Tabela 3. Coeficientes de correlação linear simples de Pearson.

\begin{tabular}{lccccccc}
\hline & TCF & TCZ & TMV & RG & DRA & RCF & PCS \\
\hline TCF & 1 & & & & & & \\
TCZ & $-0,06$ & 1 & & & & & \\
TMV & $-0,99$ & $-0,08$ & 1 & & & & \\
RG & $-0,68$ & $-0,21$ & 0,70 & 1 & & & \\
DRA & 0,46 & $-0,49$ & $-0,39$ & 0,07 & 1 & & \\
RCF & 0,40 & $-0,34$ & $-0,35$ & 0,40 & 0,66 & 1 & \\
PCS & 0,96 & $-0,09$ & $-0,94$ & $-0,76$ & 0,35 & 0,25 & 1 \\
\hline RG: & & & & & & & \\
\end{tabular}

RG: rendimento gravimétrico em carvão vegetal; RCF: rendimento em carbono fixo; DRA: densidade relativa aparente; TCF, TMV, TCZ: teor de carbono fixo, de materiais voláteis e de cinza, respectivamente; PCS: poder calorífico superior.

Observa-se alta correlação linear entre o poder calorífico superior e o teor de carbono fixo do carvão vegetal. Quanto à influência do teor de materiais voláteis no poder calorífico, percebe-se que há uma relação negativa entre essas variáveis. Os teores de carbono fixo e materiais voláteis são inversamente proporcionais, uma vez que a primeira variável é obtida por diferença.

Vale et al. (2001) encontraram uma relação linear forte e positiva $(\mathrm{r}=0,88)$ entre o poder calorífico superior e o teor de carbono fixo e negativa com o teor de materiais voláteis $(r=-0,79)$ para o carvão vegetal de diferentes espécies do cerrado, assemelhando-se ao encontrado neste trabalho. Trugilho \& Silva (2001) também encontraram uma relação linear positiva entre o poder calorífico e o teor de carbono fixo e negativa com o teor de materiais voláteis do carvão vegetal de Himenea courbaril L. De forma análoga, Protásio et al. (2011) encontraram correlação positiva e significativa entre o teor de carbono e o poder calorífico de combustíveis de biomassa vegetal.

O rendimento gravimétrico em carvão vegetal influenciou de forma negativa no poder calorífico do carvão vegetal analisado considerando-se a mesma temperatura final e taxa de carbonização da madeira. Isso ocorreu devido à correlação entre o rendimento gravimétrico e o teor de carbono fixo, ou seja, observouse que quanto menor o rendimento gravimétrico maior será o teor de carbono fixo e, consequentemente, maior será o poder calorífico do carvão vegetal. Analisando a correlação entre o teor de materiais voláteis e o rendimento gravimétrico, observou-se que há uma relação positiva entre essas variáveis, ou seja, há uma tendência estatística de que altos rendimentos em carvão vegetal estejam associados a elevados teores de materiais voláteis e vice-versa. Resultados semelhantes foram encontrados por Vale et al. (2001) que observaram uma tendência de diminuição no teor de carbono fixo e aumento no teor de materiais voláteis com o aumento no rendimento em carvão vegetal para várias espécies do bioma cerrado.

As relações lineares simples encontradas entre as características avaliadas no carvão vegetal de Qualea parviflora proveniente das diferentes posições longitudinais de amostragem estão apresentadas na Figura 8. Pode-se observar a grande relação entre as variáveis consideradas.

$\mathrm{Na}$ Tabela 4 encontram-se os modelos lineares ajustados entre as características avaliadas no carvão vegetal de Qualea parviflora, bem como o coeficiente de determinação ajustado, o coeficiente de variação, o erro padrão da estimativa e o nível de significância. 
(1)

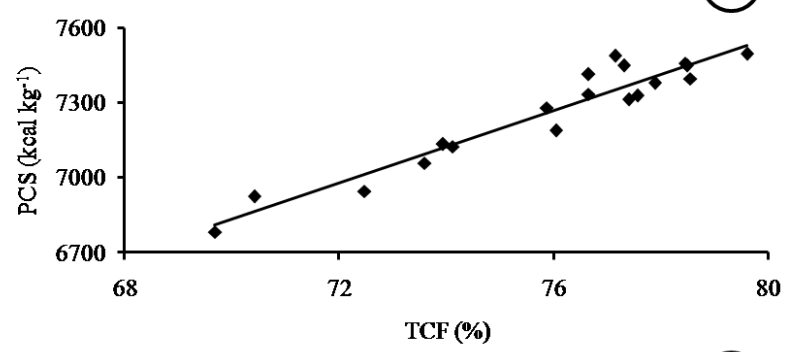

(3)

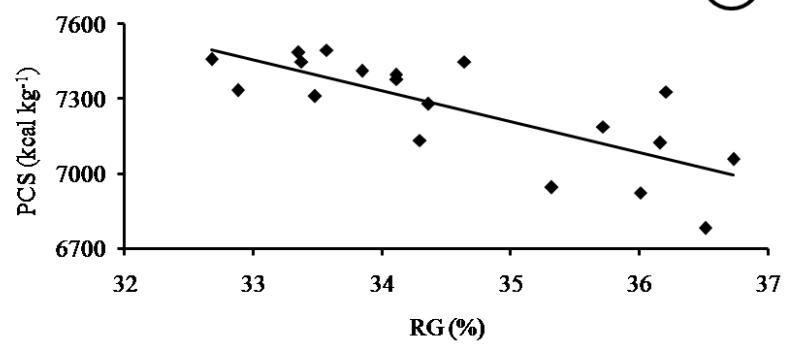

(2)

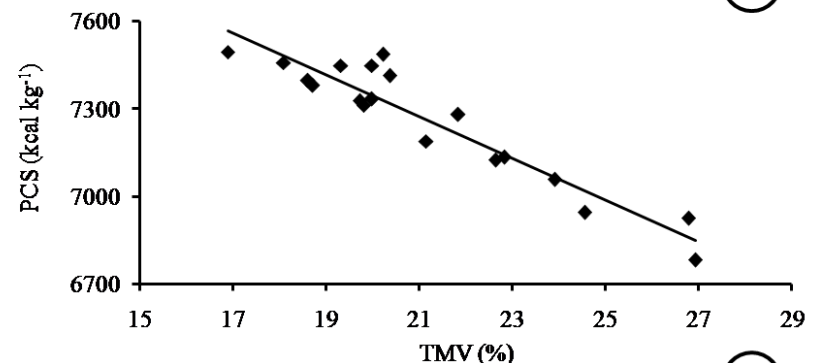

(4)

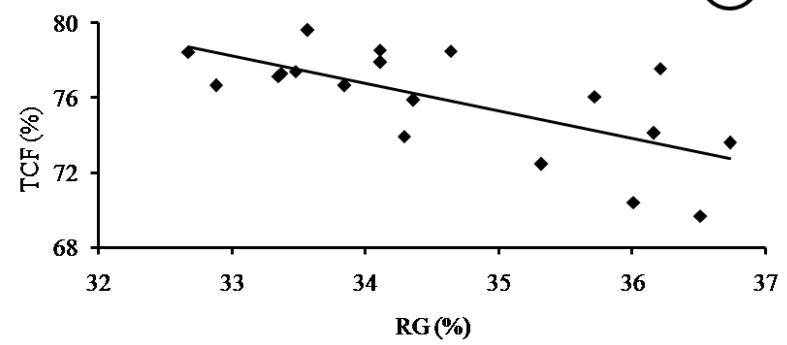

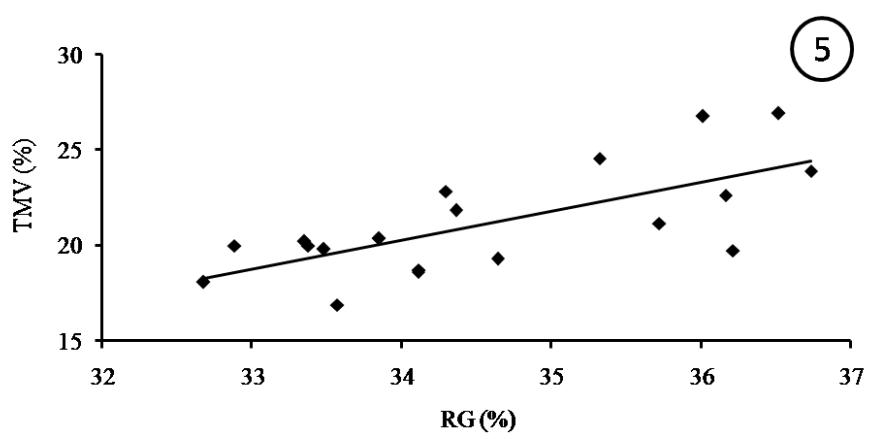

Figura 8. Modelos lineares simples ajustados entre as características avaliadas no carvão vegetal de Qualea parviflora. TCF, TMV, TCZ: teor de carbono fixo (\%), de materiais voláteis (\%) e de cinza (\%), respectivamente

Tabela 4. Modelos lineares ajustados entre as características mensuradas no carvão vegetal de Qualea parviflora.

\begin{tabular}{clcccc}
\hline $\mathbf{N}^{\mathbf{0}}$ & \multicolumn{1}{c}{ Modelos ajustados } & $\mathbf{R}^{2}$ ajust & $\mathbf{C V}$ & $\mathbf{S}_{\mathbf{x y}}$ & $\alpha$ \\
\hline 1 & PCS $=$ 72,65TCF $+1745,69$ & 0,92 & 0,85 & 61,83 & 0,0001 \\
2 & PCS $=-71,42 \mathrm{TMV}+8771,40$ & 0,89 & 0,99 & 71,71 & 0,0001 \\
3 & PCS $=-124,11 \mathrm{RG}+11553,08$ & 0,58 & 1,95 & 141,8 & 0,0001 \\
4 & TCF $=-1,46 \mathrm{RG}+126,35$ & 0,46 & 2,79 & 2,12 & 0,001 \\
5 & TMV $=1,52 \mathrm{RG}-31,49$ & 0,50 & 9,66 & 2,05 & 0,001 \\
6 & PCS $=3696,05+62,18 \mathrm{TCF}-33,41 \mathrm{RG}$ & 0,94 & 0,74 & 54,01 & 0,0001 \\
7 & PCS $=9617,48-61,47 \mathrm{TMV}-30,55 \mathrm{RG}$ & 0,90 & 0,93 & 67,65 & 0,0001 \\
\hline
\end{tabular}

RG: rendimento gravimétrico em carvão vegetal (\%); RCF: rendimento em carbono fixo (\%); TCF, TMV, TCZ: teor de carbono fixo (\%), de materiais voláteis (\%) e de cinza (\%), respectivamente; PCS: poder calorífico superior ( $\left.\mathrm{kcal} \mathrm{kg}^{-1}\right) ; \mathrm{R}^{2}$ ajust: coeficiente de determinação ajustado; CV: coeficiente de variação (\%); Sxy: erro padrão da estimativa; $\alpha$ : nível de significância do modelo pelo Teste $F$. 
Pode-se observar que todos os modelos ajustados foram altamente significativos pelo Teste F. O modelo 1 que relaciona o PCS com o TCF apresentou elevado coeficiente de determinação, todos os coeficientes significativos pelo teste $\mathrm{t}$ ( $\mathrm{p}$-valor $<0,001$ ), normalidade $(\mathrm{p}$-valor $=0,1990)$, homocedasticidade $(\mathrm{p}$-valor $=$ $0,6427)$ e ausência de autocorrelação $(p-v a l o r=0,6300)$ dos resíduos da equação ajustada, atendendo assim aos pressupostos da análise de regressão linear simples. Analisando o coeficiente $\beta_{1}$ do modelo, percebe-se que a cada $1 \%$ de acréscimo no TCF ocorre um aumento de $72,65 \mathrm{kcal} \mathrm{kg}^{-1}$ no PCS, assemelhando a 74,06 kcal $\mathrm{kg}^{-1}$ encontrado por Vale et al. (2001). Esse resultado demonstra a grande influência da primeira variável mencionada no poder calorífico do carvão vegetal. Observa-se ainda que o modelo 1 apresentou baixo coeficiente de variação e baixo erro padrão da estimativa, ou seja, os pontos observados estão próximos da reta média ajustada. Esses resultados indicam que o modelo ajustado 1 pode ser utilizado para predições e interpretações de interesse.

Analisando-se o ajuste 2, percebe-se a influência negativa do TMV no PCS, ou seja, a cada $1 \%$ de acréscimo no TMV ocorre um decréscimo de $71,42 \mathrm{kcal}$ $\mathrm{kg}^{-1}$ no PCS do carvão vegetal de Qualea parviflora. O modelo ajustado 2 , à semelhança do modelo 1 , apresentou todos os coeficientes altamente significativos ( $p$-valor $<0,001$ ), elevado coeficiente de determinação, baixo coeficiente de variação, baixo erro padrão da estimativa, ausência de autocorrelação (p-valor = $0,9038)$ e homocedasticidade $(\mathrm{p}$-valor $=0,6567)$ dos resíduos. Entretanto, não apresentou normalidade residual em nível de $5 \%$ de significância pelo Teste Shapiro-Wilk ( $\mathrm{p}$-valor $=0,0233$ ). Para construir testes de hipóteses ou intervalos de confiança, é preciso que o modelo apresente normalidade residual. Além disso, desvios em relação à normalidade podem influenciar as estatísticas t e F, comprometendo as inferências relacionadas ao modelo (Werkema \& Aguiar, 2006).

O modelo ajustado 3 relaciona o elevado PCS ao baixo rendimento em carvão vegetal. Todos os coeficientes do modelo foram significativos pelo teste $\mathrm{t}$ ( $\mathrm{p}$-valor $<$ 0,001), mas o coeficiente de determinação encontrado foi baixo. Esse resultado demonstra que a variabilidade no PCS do carvão analisado não foi suficientemente explicada pelo RG. Não foram detectados desvios em relação à normalidade $(\mathrm{p}$-valor $=0,2637) \mathrm{e}$ homocedasticidade $(0,4033)$ residuais. No entanto, os resíduos do modelo apresentaram autocorrelação residual em nível de $5 \%$ de significância pelo teste Durbin-Watson ( $\mathrm{p}$-valor $=0,01157)$. A presença de autocorrelação residual exerce um grande efeito sobre a qualidade dos estimadores de mínimos quadrados para $\beta_{0}$ e $\beta_{1}$ e pode ser uma consequência da não inclusão de uma variável importante no modelo (Werkema \& Aguiar, 2006). Observa-se ainda que o modelo 3 apresentou erro padrão da estimativa superior aos modelos 1 e 2, ou seja, os dados apresentam-se mais dispersos ao redor da reta média ajustada.

Observando-se os modelos ajustados 4 e 5 percebemse baixos coeficientes de determinação, ou seja, para o carvão vegetal analisado proveniente de diferentes posições longitudinais de amostragem em Qualea parviflora, os teores de carbono fixo e materiais voláteis não foram suficientemente explicados pelo rendimento gravimétrico. Contudo, esses modelos apresentaram todos os coeficientes significativos pelo teste $\mathrm{t}$ ( $\mathrm{p}$-valor $<$ $0,05)$. Os resíduos do modelo 4 atenderam as suposições de normalidade $(\mathrm{p}$-valor $=0,7579)$ e homocedasticidade $(\mathrm{p}$-valor $=0,7676)$, mas apresentaram autocorrelação a 5\% de significância pelo Teste de Durbin-Watson ( $\mathrm{p}$-valor = 0,01278). Já os resíduos do modelo 5 atenderam a todos os pressupostos da análise de regressão linear avaliados, ou seja, normalidade ( $\mathrm{p}$-valor $=0,9530$ ), homocedasticidade ( $p$-valor $=0,8084)$ e ausência de autocorrelação ( $p$-valor $=0,05857)$. Entretanto, o modelo 5 apresentou o maior coeficiente de variação entre os modelos ajustados.

Avaliando-se os modelos múltiplos 6 e 7, pode-se perceber elevados coeficientes de determinação, baixos coeficientes de variação e baixos erros padrões da estimativa. O modelo 6 relaciona o carvão vegetal de alto PCS com alto TCF e baixo RG. Observa-se que a cada $1 \%$ de acréscimo no TCF ocorre um aumento de $62,18 \mathrm{kcal} \mathrm{kg}^{-1}$ no PCS, assemelhando ao encontrado para o modelo 1 . Resultado diferente pode ser obtido ao avaliarmos o sinal do coeficiente $\beta_{2}$, ou seja, a cada $1 \%$ de acréscimo no RG ocorre um decréscimo de 33,41 $\mathrm{kcal} \mathrm{kg}^{-1}$ no PCS. Não foram observadas violações nos pressupostos da análise de regressão linear simples, ou seja, o modelo ajustado apresentou normalidade (p-valor $=0,6550)$, homocedasticidade $(\mathrm{p}$-valor $=0,2729) \mathrm{e}$ ausência de autocorrelação dos resíduos (p-valor = 0,5094). Dessa forma, o modelo linear múltiplo proposto que relaciona o PCS com o TCF e o RG do carvão vegetal de Qualea parviflora pode ser utilizado para predições e interpretações de interesse. 
Analisando-se o modelo 7, observa-se que o aumento no PCS está relacionado à diminuição do teor de materiais voláteis e no rendimento gravimétrico, ou seja, a cada $1 \%$ de acréscimo no TMV ocorre um decréscimo no PCS de $61,47 \mathrm{kcal} \mathrm{kg}^{-1}$. De forma análoga, podese inferir que a cada $1 \%$ de acréscimo no $\mathrm{RG}$ ocorre um decréscimo de $30,55 \mathrm{kcal} \mathrm{kg}^{-1}$, assemelhando ao encontrado para o modelo 6 . No entanto, o coeficiente $\beta_{2}$ do modelo não foi significativo pelo teste t a $5 \%$ (p-valor $=0,0972)$, os demais coeficientes foram altamente significativos ( $\mathrm{p}$-valor $<0,0001)$. Quanto à análise de resíduos, observou-se normalidade ( $\mathrm{p}$-valor $=0,0760$ ), homocedasticidade ( $\mathrm{p}$-valor $=0,3197)$ e ausência de autocorrelação ( $\mathrm{p}$-valor $=0,5945)$. Esses resultados comprovam a qualidade do ajuste obtido.

Considerando-se as relações lineares múltiplas obtidas entre o poder calorífico superior e os teores de carbono fixo e materiais voláteis e o rendimento gravimétrico

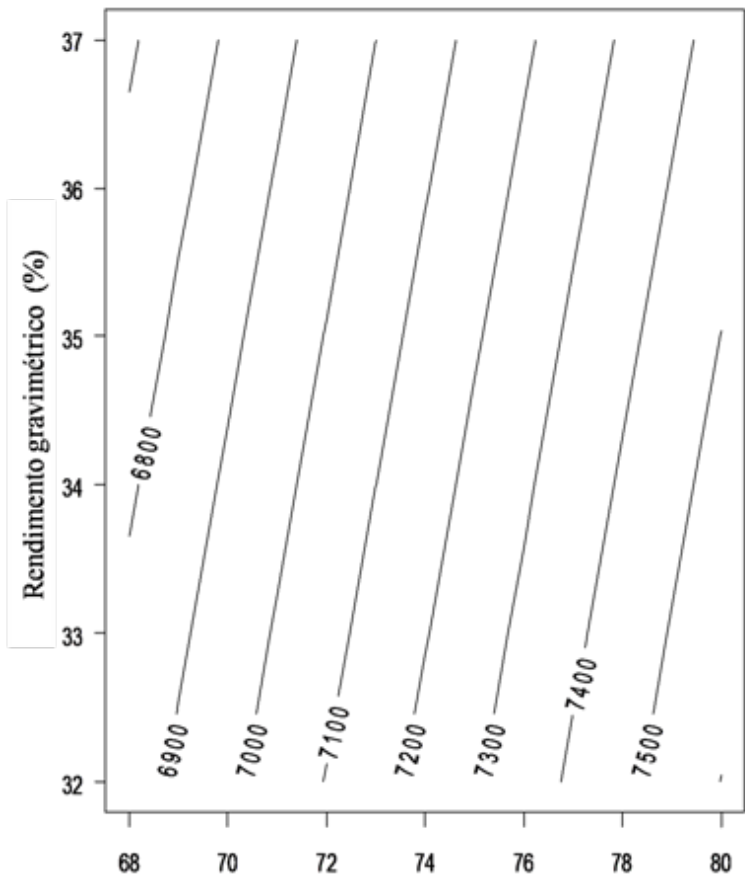

Teor de carbono fixo (\%)

Figura 9. Gráficos de contorno dos modelos múltiplos ajustados. do carvão vegetal de Qualea parviflora, observa-se a influência positiva do TCF e negativa do TMV e RG no PCS, demonstrando a grande importância dessas variáveis no desempenho energético do carvão vegetal de Qualea parviflora.

De forma geral, visando à otimização do poder calorífico superior do carvão vegetal de Qualea parviflora e a sua utilização como fonte de energia renovável, deve-se considerar o teor de carbono fixo, o rendimento gravimétrico e o teor de materiais voláteis como as principais características relacionadas à sua qualidade energética. Com base na avaliação dos gráficos de contorno (Figura 9), percebe-se que o maior poder calorífico superior do carvão vegetal está compreendido entre $33 \%$ e $34 \%$ de rendimento gravimétrico, $78 \%$ e $80 \%$ de carbono fixo e $18 \%$ de materiais voláteis, aproximadamente.

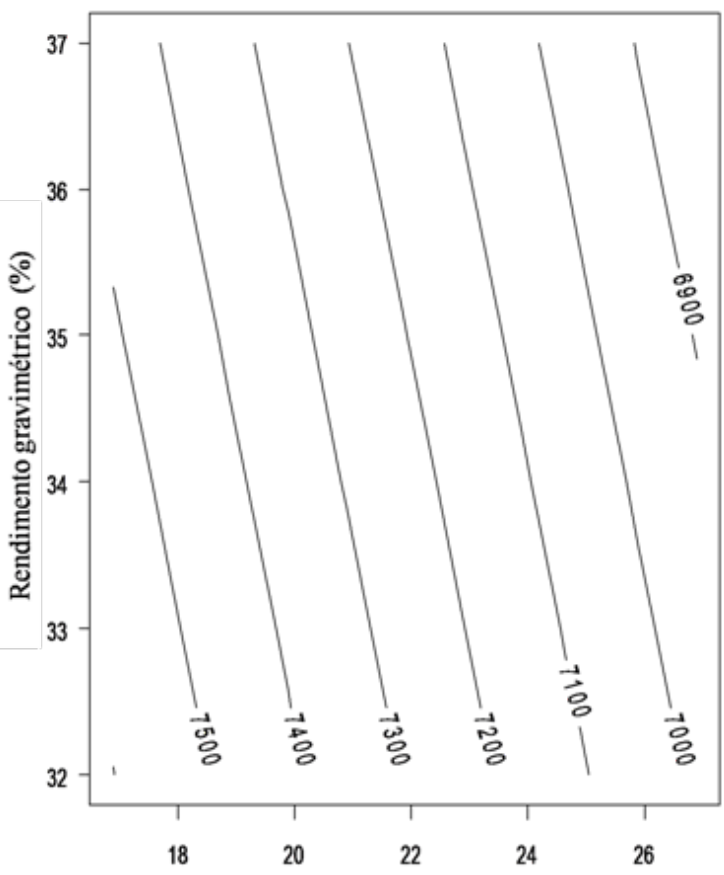

Teor de materiais voláteis (\%)
O carvão vegetal proveniente da madeira de Qualea parviflora apresentou grande potencial energético, assemelhando ao carvão vegetal de várias espécies e clones de Eucalyptus comumente relatados na literatura
(Brito \& Barrichelo, 1977; Oliveira et al., 1989; Trugilho et al., 2001; Trugilho et al., 2005; Botrel et al., 2007; Oliveira et al., 2010; Lima et al., 2011) e de outras espécies do cerrado brasileiro (Vale et al., 1996; Vale et al., 2001). 


\section{Conclusões}

O carvão vegetal proveniente da madeira de Qualea parviflora apresenta grande potencial energético. De maneira geral, não foi constatada influência significativa da posição longitudinal de amostragem em Qualea parviflora na qualidade do carvão vegetal.

Observaram-se significativas correlações lineares entre as características avaliadas no carvão vegetal analisado. Os modelos ajustados 1, 6 e 7 podem ser considerados, de maneira geral, os mais adequados para predições e interpretações de interesse.

Deve-se considerar o teor de carbono fixo, o rendimento gravimétrico e o teor de materiais voláteis como as principais características relacionadas ao poder calorífico superior do carvão vegetal de Qualea parviflora.

\section{Referências}

ASSOCIAÇÃO BRASILEIRA DE NORMAS TÉCNICAS. NBR 8112: Análise imediata: material volátil, cinzas, carbono fixo. Rio de Janeiro, 1983. 6 p.

ASSOCIAÇÃO BRASILEIRA DE NORMAS TÉCNICAS. NBR 8633: Carvão vegetal: determinação do poder calorífico. Rio de Janeiro, 1984. 13 p.

BOTREL, M. C. G.; TRUGILHO, P. F.; ROSADO, S. C. S.; SILVA, J. R. M. Melhoramento genético das propriedades do carvão vegetal de Eucalyptus. Revista Árvore, Viçosa, MG, v. 31, n. 3, p. 391-398, 2007

BRAND, M. A. Energia de biomassa florestal. Rio de Janeiro: Interciência, 2010. 131 p.

BRITO, J. O. O uso energético da madeira. Estudos avançados, São Paulo, v. 21, n. 59, p. 185-193, 2007.

BRITO, J. O.; BARRICHELO, L. E. G. Correlações entre características físicas e químicas da madeira e a produção de carvão vegetal: I. densidade e teor de lignina da madeira de eucalipto. IPEF, Piracicaba, SP, n. 14, p. 9-20, 1977.

BRITO, J. O.; BARRICHELO, L. E. G. Correlações entre características físicas e químicas da madeira e a produção de carvão: II. densidade da madeira $\mathrm{x}$ densidade do carvão. IPEF, Piracicaba, SP, n. 20, p. 101-113, 1980.

BRITO, J. O.; BARRICHELO, L. E. G.; MIGLIORINI, A. J.; MURAMOTO, M. C. Análise da produção energética e de carvão vegetal de espécies de eucalipto. IPEF, Piracicaba, SP, n. 23, p. 53-56, 1983.

CALAIS, D. Florestas energéticas no Brasil: demanda e disponibilidade. [Belo Horizonte]: Associação Mineira de Silvicultura, 2009. 23 p. Disponível em: $<$ http://www.silviminas.com. br/arquivo/publicacoes.aspx?ano=23>. Acesso em: 12 jul. 2011.
HOTHORN, T.; ZEILEIS, A.; MILLO, G.; MITCHELL, D. Testing linear regression models. R package version 2.11.1. Disponível em: cranr.c3sl.ufpr.br. Acesso em: 23 out. 2011.

LIMA, E. A.; SILVA, H. D.; LAVORANTI, O. J. Caracterização dendroenergética de árvores de Eucalyptus benthamii. Pesquisa Florestal Brasileira, Colombo, PR, v. 31, n. 65, p. 09-17, 2011.

LORENZI, H. Árvores brasileiras: manual de identificação e cultivo de plantas arbóreas do Brasil 2. ed. Nova Odessa, SP: Plantarum, 2002. 368 p. v. 2.

NOGUEIRA, L. A. H.; LORA, E. E. S. Dendroenergia: fundamentos e aplicações. 2. ed. Rio de Janeiro: Interciência, 2003. 199 p.

OLIVEIRA, A. C.; CANEIRO, A. C. O.; VITAL, B. R.; ALMEIDA, W.; PEREIRA, B. L. C.; CARDOSO, M. T. Parâmetros de qualidade da madeira e do carvão vegetal de Eucalyptus pellita F. Muell. Scientia Forestalis, Piracicaba, SP, v. 38 , n. 87, p. 431-439, 2010.

OLIVEIRA, E.; VITAL, B. R.; VALENTE, O. F.; GOMIDE, J. L. Efeito da qualidade da madeira sobre o rendimento e qualidade do carvão de Eucalyptus grandis. Revista Árvore, Viçosa, MG, v. 13, n. 1, p. 85-97, 1989.

PIMENTEL-GOMES, F. Curso de estatística experimental. 15. ed. Piracicaba, SP: FEALQ, 2009. 451 p.

PINHEIRO, P. C. C.; VIANA, E.; REZENDE, M. E. A.; SAMPAIO, R. S. A produção de carvão vegetal. Belo Horizonte: [s.n.], 2006. $103 \mathrm{p}$.

PROTÁSIO, T. P.; BUFALINO, L.; TONOLI, G. H. D.; COUTO, A. M.; TRUGILHO, P. F.; GUIMARÃES JÚNIOR, M. Relação entre o poder calorífico superior e os componentes elementares e minerais da biomassa vegetal. Pesquisa Florestal Brasileira, Colombo, PR, v. 31, n. 66, p. 122-133, 2011.

R DEVELOPMENT CORE TEAM. R: a language and environment for statistical computing. Vienna, Austria: R Foundation for Statistical Computing, 2008. Disponível em: $<$ http://www.R-project.org>. Acesso em: 10 dez. 2010.

ROSILLO-CALLE, F.; BEZZON, G. Produção e uso industriais do carvão vegetal. In: ROSILLO-CALLE, F.; BAJAY, S. V.; ROTHMAN, H. Uso da biomassa para a produção de energia na indústria brasileira. Campinas, SP: Unicamp, 2005. 447 p.

TRUGILHO, P. F.; LIMA, J. T.; MORI, F. A; LINO, A. L. Avaliação de clones de Eucalyptus para a produção de carvão vegetal. Cerne, Lavras, MG, v. 7, n. 2, p. 104-114, 2001.

TRUGILHO, P. F.; SILVA, D. A. Influência da temperatura final de carbonização nas características físicas e químicas do carvão vegetal de jatobá (Himenea courbaril L.). Scientia Agraria, Curitiba, PR, v. 2, n. 1-2, p. 45-53, 2001.

TRUGILHO, P. F.; SILVA, J. R. M.; MORI, F. A.; LIMA, J. T.; MENDES, L. M.; MENDES, L. F. B. Rendimentos e características do carvão vegetal em função da posição radial de amostragem em clones de Eucalyptus. Cerne, Lavras, MG, v. 11, n. 2 , p. $178-186,2005$. 
VALE, A. T.; BRASIL, M. A. M.; LEÃO, A. L. Disponibilidade de energia na forma de calor da biomassa lenhosa de um cerrado sensu stricto da região de Brasília. In: ENCONTRO DE ENERGIA NO MEIO RURAL, 3., 2000, Campinas. Anais... Campinas: AGRENER, 2000.

VALE, A. T.; COSTA, A. F.; GONÇALEZ, J. C.; NOGUEIRA, M. Relações entre a densidade básica da madeira, o rendimento e a qualidade do carvão vegetal de espécies do cerrado. Revista Árvore, Viçosa, MG, v. 25, n. 89, p. 89-95, 2001.

VALE, A. T.; DIAS, I. S.; SANTANA, M. A. E. Relações entre propriedades químicas, físicas e energéticas da madeira de cinco espécies de cerrado. Ciência Florestal, Santa Maria, RS, v. 20, n. 1, p. 137-145, 2010.
VALE, A. T.; FIEDLER, N. C.; SILVA, G. F. Avaliação energética da biomassa do cerrado em função do diâmetro das árvores.

Ciência Florestal, Santa Maria, RS, v. 12, n. 2, p. 115-126, 2002.

VALE, A. T.; NOGUEIRA, M. V. P.; SILVA, M. A. Rendimento da carbonização e qualidade do carvão vegetal de madeiras do cerrado em comparação ao Eucalyptus grandis. Revista Árvore, Viçosa, MG, v. 20, n. 1, p. 93-99, 1996.

VITAL, B. R. Métodos de determinação da densidade da madeira. Viçosa, MG: SIF, 1984. 21p. (Boletim técnico, 1). WERKEMA, C.; AGUIAR, S. Análise de regressão: como entender o relacionamento das variáveis de um processo. Belo Horizonte: Werkema, 2006. 306 p. 
